\title{
Um breve ensaio sobre a "interpretação das interpretações" a partir de um texto de Michel Foucault
}

\author{
JEAN D. SOARES * \\ * Doutorando em Filosofia \\ na PUC - Rio \\ jeandyego@gmail.com
}

\begin{abstract}
RESUMO Sem a pretensão de uma exposição sistemática, este texto constitui um exercício: pensar o que constituiria uma interpretação das interpretações tal como sugere Michel Foucault em seu texto intitulado Nietzsche, Freud e Marx. Salientamos a importância por ele dada às atitudes desafiadoras dos três autores, enquanto pensadores que se notabilizaram por se situar em um nível de análise que presa por proporcionar outros meios para interpretar as interpretações que lhes cercam, ampliando continuamente o horizonte interpretativo. Nosso objetivo consiste em mostrar como essa reflexão sobre o ato de interpretar constitui gesto importante para o entendimento da postura do autor sobre a linguagem.
\end{abstract}

PALAVRAS-ChAVE Foucault, Interpretação, Hermenêutica da suspeita.

ABSTRACT Without a commitement with a systematic account, this paper intends to be an exercise on thinking what could be an interpretation of interpretation as such as Michel Foucaul suggests in his well-known conference "Nietzsche, Freud e Marx. We stress the importance given for Foucault to these three authors, while thinkers which are known for setting their researches in a level of analyses which allows others ways to interpret which kind of interpretations are around us, getting the interpretative horizon wider. Our aim is to show how these reflection about the act of interpret could be important to understand the position of Foucault about language.

KEYWORDS Foucault, Interpretation, Hermeneutics of suspicious.

Eм um texto de 1967, intitulado Nietzsche, Freud, Marx, Michel Foucault estuda como a partir desses três nomes o espaço da interpretação se alterou radicalmente. Um detalhe chama a atenção. Um primeiro: ele fala ali da necessidade de fazer uma "Enciclopédia" ou uma "história das técnicas de interpretação", sintagma com estrutura semelhante ao usado por ele para nomear, anos depois, sua disciplina no Collége de 
France - "história dos sistemas de pensamento". De modo a introduzir o leitor nessa história das técnicas de interpretação, Foucault explicita dois tipos de suspeita despertados pela linguagem: - a de que ela não diz exatamente o que diz; e a de que “ela ultrapassa sua forma propriamente verbal, que há certamente no mundo outras coisas que falam e não são linguagem.” Para ele desde os gregos até nós uma certa história poderia ser traçada perseguindo essas duas suspeitas. Se para os gregos, allegoria e huponóia podem ser vistas como meios pelos quais percebem isto que não diz exatamente o que diz, o semainon caracterizava essa relação de ultrapassagem dos limites verbais da linguagem - através dos signos algo mais se manifestava que não o meramente linguístico, verbal. Após essa rápida citação de termos gregos, Foucault retoma a questão da semelhança, trabalhada por ele em As palavras e as coisas (1966). Tanto lá, quanto aqui neste texto, a unidade mínima que, até o século, XVI, a interpretação tinha de tratar era a semelhança. O que aos nossos olhos pode parecer confuso - como a divisão dos animais de uma certa enciclopédia chinesa - em verdade apresenta uma ampla rede de similitudes na qual os signos se aproximam por conveniência (convenientia), simpatia (sympatheia), emulação (emulatio), assinatura (signatura) e analogia. Através dessas formas, detalhadamente exemplificadas pelo autor em seu livro de $1966^{3}$ no capítulo sobre “A prosa do mundo", tudo possui algum parentesco possível com tudo e à técnica de interpretação em questão caberia entender como, através dessas figuras, as semelhanças aparecem.

Com a crítica de Bacon e Descartes ao reinado da semelhança no interior das técnicas de interpretação ${ }^{4}$, estas serão colocadas em suspenso até o século XIX quando de maneira muito específica Nietzsche, Freud e Marx suscitam um novo capítulo nessa

1 Quando sugere pensar tais técnicas de interpretação, Foucault procura analisar o modo pelo qual se desenvolveram as diversas técnicas de delimitação do sentido no discurso ao longo do tempo. Quando procura escrever uma história dos sistemas de pensamento, não se trata só de perceber como o sentido é produzido, mas de como ele está inserido em um sistema, em uma ordem, em um conjunto de práticas que pretendem formar uma determinada maneira de produzir verdades e sujeitos (Cf. Sobre isso A ordem do discurso, p. 60 et seq.). Em resumo, se no primeiro caso, se tratava de perceber como os jogos de interpretação atravessam os discursos, no segundo, o trabalho se estende ao que não é discursivo, a essa imbricação que, num sistema de pensamento, reúne o que se pensa ao que age e ao que é pensado.

2 FOUCAULT, “Nietzsche, Freud, Marx”, DE1, pp. 564-5 [p. 40].

3 FOUCAULT, Les mots e les choses, pp. 32-60.

4 FOUCAUlT, “Nietzsche, Freud, Marx”, DE1, pp. 566 [p. 42]. 
história das técnicas de interpretação. Para apoiar essa sugestão Foucault aborda três temas: o das condições de distribuição dos signos em um espaço linguístico; o do inacabado das interpretações; e o da retomada das interpretações. Os três temas situam um ponto de retomada comum desses três pensadores: os três teriam sido notáveis por não buscar uma origem primeira e profunda, um espaço do qual os sentidos e os signos viriam. Muito pelo contrário, eles teriam se notabilizado por mostrar como na superfície mesma do que falamos podemos notar as relações interpretativas, os laços produzidos, as forças e jogos em causa. Tanto o processo de livre associação de Freud, quanto a genealogia de Nietzsche, bem como a análise da ideologia de Marx preterem um mergulho nas profundezas dos tempos em privilégio de uma análise que interpreta o meio pelo qual se dão as interpretações. Um valor moral como bem ou mal, um sonho ou um ato falho, ou mesmo um fetiche são meios pelos quais se interpretam o mundo que, em sua superficialidade permitem Nietzsche, Freud e Marx interpretar tais interpretações;

É curioso perceber como “ponto de ruptura da interpretação” em uma direção que a tornaria impossível, um tema tão importante para Foucault, citado neste texto, qual seja “a experiência da loucura”. Sua relação com o assunto sugere o retorno constante de uma experiência limite que não só o impressiona como talvez o ameace, como fez a Freud ${ }^{5}$ ou a Nietzsche, que foi tomado por ela ${ }^{6}$. Para Foucault essa ameaça sugere contínua de poder enlouquecer sugere que a experiência da loucura desafia o hermeneuta, uma vez que sua interpretação racional liga-se continuamente a discursos continuamente em mutação, que resistem sem cessar a interpretações definitivas. Daí a possível violência do gesto do intérprete, uma vez diante da impossibilidade de firmar razões, ou mesmo da desrazão, ele ainda insiste em procurar a verdadeira interpretação daquilo que sempre oferece novas possibilidades ${ }^{7}$. Nietzsche, Freud e Marx teriam situado seus trabalhos, como espécies de 'psicólogos' no interior dessa experiência de interpretação das interpretações. Ainda aqui gostaria de me deter, citando Foucault:

5 Um exemplo da fragilidade desses limites foi proporcionado por Freud ao analisar o caso "Schereber”, onde se lê: “o futuro decidirá se na teoria há mais delírio do que eu penso, ou se no delírio há mais verdade do que outros atualmente acreditam" (FREUD, 2010, p. 103).

6 Cf. FOUCAULT, “Nietzsche, Freud, Marx”, DE1, pp. 570-1 [p. 46].

7 Cf. FOUCAULT, História da loucura na idade clássica. 
Nada há de absolutamente primeiro a interpretar, pois no fundo, tudo já é interpretado, cada signo é em si mesmo não algo que se oferece à interpretação, mas interpretação de outros signos. (...) Com efeito, a interpretação não esclarece uma matéria a interpretar, que se oferece a ela passivamente. Ela só pode se apoderar, e violentamente, de uma interpretação já ali, que deve subverter, revirar, quebrar a marteladas. ${ }^{8}$

Interpretação das interpretações dos valores, interpretação das interpretações do corpo, interpretações das interpretações das relações de produção - poderíamos definir assim o trabalho de Nietzsche, Freud e Marx, respectivamente. O que me chama a atenção é a sugestão de violência que este gesto impõe. Eles são violentos porque pretendem não estabelecer como se deve avaliar a interpretação do próprio gesto, mas sim chamar a atenção para a importância de interpretar. Os exemplos são esclarecedores. No caso dos atos falhos, dos sonhos ou dos chistes ao estabelecê-los como objetos de análise, Freud dá dignidade àquilo que era impensável ou irrepresentável, torna-o objeto de interpretação, e chama a atenção para importância daquilo que era excluído, como gesto errado, anormal ou estranho, sem pretender-lhe uma origem primeira ou um sentido originário. Freud não busca a boa ou a má interpretação para um sem número de gestos - trata-se de interpretar o que chamamos de falho, engraçado, o que chamamos de nobre, de mal, de bom, de verdadeiro. Isso, evidentemente nos colocaria diante de uma tarefa infinita que só se rompe pela violência das semelhanças, ou se preferirmos o vocabulário da microfísica, pela força de uma interpretação convincente - e, quem sabe, só enquanto dura o seu convencimento. Daí por exemplo, a possibilidade de reinterpretar as perspectivas sobre um ato falho, um valor moral ou sobre as relações de produção em uma dada época. Poderíamos sugerir algo parecido partindo do aforismo "Nosso novo infinito", no qual lemos Nietzsche a dizer:

Até onde vai o caráter perspectivista da existência, ou mesmo se ela tem algum outro caráter, se uma existência sem interpretação, sem 'sentido' [Sinn], não vem a ser justamente 'absurda' [Unsinn], se, por outro lado, toda a existência não é essencialmente interpretativa - isso não pode, como é razoável, ser decidido nem pela mais diligente e conscienciosa análise e autoexame do intelecto: pois nessa análise o intelecto humano não pode deixar de ver a si mesmo sob suas perspectivas e apenas nelas. Não podemos enxergar além de nossa esquina: é uma curiosidade desesperada querer saber que outros tipos de intelectos

8 Cf. FOUCAULT, “Nietzsche, Freud, Marx”, DE1, pp. 571 [p. 47]. 
e perspectivas poderia haver: por exemplo, se quaisquer outros seres podem sentir o tempo retroativamente ou, alternando, progressiva ou regressivamente (com o que se teria uma orientação da vida e uma outra noção de causa e efeito). Mas penso que hoje, pelo menos, estamos distanciados da ridícula imodéstia de decretar, a partir de nosso ângulo, que somente dele pode-se ter perspectivas. $\mathrm{O}$ mundo tornou-se novamente infinito para nós: na medida em que não podemos rejeitar a possibilidade de que ele encerre infinitas interpretações." 9

Trata-se, nesse aforismo de A gaia ciência do mesmo exercício de interpretar a possibilidade de interpretações, ciente da dificuldade radical do intelecto de fazer um autoexame. Nietzsche assume a nossa condição paradoxal - não estamos em uma condição suficientemente apta para decidir se uma existência sem interpretação é absurda ou não - daí a necessidade de estar atento ao risco da interpretação, aos valores implicados em cada uma delas. Uma vez que o mundo, após a superação das dicotomias cristãs e utilitaristas, se torna novamente infinito, uma gaia ciência não deve rejeitar a possibilidade de que as interpretações se multipiquem infinitamente. Isso não significa afirmar a impossibilidade de interpretar, mas sim de que as perspectivas são múltiplas e seu confronto faz proliferar ao infinito esse jogo. Nietzsche parece sugerir que nossas limitações não nos devem impedir de interpretar, desde cientes de que essa interpretação pode ser sucedida por outras, infinitamente.

Poderíamos também recorrer ao celebre aforismo de Marx, já tão citado, quando diz que “Os filósofos se limitaram a interpretar o mundo de diferentes maneiras; mas o que importa é transformá-10"10. Nesse aforismo das Teses, uma vez mais temos um exemplo da interpretação das interpretações de que fala Foucault. Aqui Marx se contrapõe a uma atitude teórica típica de sua época, qual seja a de se limitar a estudar e interpretar o mundo sem se comprometer com a ação de sua interpretação. Nesta constatação já está contida uma interpretação das interpretações. Marx interpreta a atitude interpreta dos filósofos como limitada, e sugere a necessidade de transforma o mundo, o que passa por conectar essa capacidade de pensá-lo de diversas maneiras à de agir diferentemente, alterando o mundo, e consequentemente, as interpretações usuais que dele se têm. A incitação no sentido de transformá-lo sugere a possibilidade ressignificar os nossos modos de produzir novas coisas e interpretações, infinitamente.

9 NIETZSCHE, 2001, p. 278, § 374 .

10 MARX, Teses sobre Feuerbach, XI. 
Através desses casos, esboçamos rapidamente como partindo da suspeita de que a linguagem não diz tudo o que diz, os pensadores da suspeita desenvolveram técnicas que lhes permitiram interpretar as interpretações. Ao abordaram as interpretações através da superficialidade presente, sem recorrer a origens remotas, assumindo o caráter inacabado e infinito de suas tarefas, essas pensadores retomaram uma atitude diante da linguagem que resgata os potenciais esquecidos desde a revolução científica e a episteme da representação. Análises estas que não cessam de se implicar elas mesmas em sua atividade de modo a inserir no horizonte de interpretação aquele mesmo que interpreta, expondo assim a infinitude de sua tarefa. Estaria Foucault, ao interpretá-los por essa via, reafirmando a infinitude desta tarefa? Certamente, pois como ele mesmo sugere "a vida das interpretações é acreditar que só há interpretações" em um jogo que se multiplica como as entradas da “enciclopédia chinesa” imaginada por Borges. Com isso, Foucault parece querer combater uma hermenêutica que acredita na existência absoluta dos signos - sem questionar o quanto a sua superfície se rarefaz através daquele que faz uso dos signos em um determinado tempo. Tornou-se possível depois de Nietzsche, Freud e Marx perceber que a história das interpretações altera disposições e abre lacunas, espaços que mantém a vida das semelhanças. Nessa possibilidade arbitrária de perceber que na superfície do dito há mais do que simplesmente signos - há falantes, estratégias de subjetivação, poderes, etc. - que uma grande suspeita interpretativa, uma curiosidade contínua não cessa de investigar.

\section{BIBLIOGRAFIA PRIMÁRIA}

FOUCAULT, M. A coragem da verdade. Trad. E. Brandão. São Paulo: Martins Fontes, 2011. A hermenêutica do sujeito. Trad. M. Fonseca. São Paulo: Martins Fontes, 2004. . A ordem do discurso. Trad. Laura Sampaio. São Paulo: Loyola, 2009. Dits et écrits. 4 tomos. Paris: Gallimard, 1994. . História da sexualidade 1: a vontade de saber. Rio de Janeiro: Graal, 1977. . História da sexualidade 2: o uso dos prazeres. Rio de Janeiro: Graal, 1984. . L'archéologie du savoir. Paris: Gallimard, 1969. 
Les mots et les choses. Paris: Gallimard, 1966.

. L'ordre du discours. Paris: Gallimard, 1971.

_. Leçons sur la volonté du savoir. Paris: Gallimard, 2011.

—. O governo de si e dos outros. Trad. Eduardo Brandão. São Paulo: Martins Fontes, 2010.

\section{BIBLIOGRAFIA SECUNDÁRIA E OUTROS TEXTOS}

CASTRO, E. Vocabulário de Foucault. Trad. Ingrid Xavier. Belo Horizonte: Autêntica, 2009.

DREYFUS, H. RABINOW, P. Michel Foucault, uma trajetória filosófica. Trad. Vera Portocarrero. Rio de Janeiro: Forense Universitária, 2013. $2^{\mathrm{a}} \mathrm{Ed}$.

ERIBON, D. Michel Foucault: uma biografia. Trad. H. Feist. São Paulo: Companhia das Letras, 1989.

FREUD, S. Observações psicanalíticas sobre um caso de paranoia relatado em autobiografia (“O caso Schereber”), artigos sobre técnica e outros textos [1911-1913]. Trad. Paulo César de Souza. São Paulo: Companhia das Letras, 2010.

MARX, Karl. Teses sobre Feuerbach [1845]. Trad. anônima. (Acessada em 1 de abril de 2016 no endereço http://laurocampos.org.br/2008/03/onze-teses-sobre-feuerbach/).

NIETZSCHE, F. A Gaia Ciência. Trad. Paulo César de Souza. São Paulo: Companhia das Letras, 2001.

SOARES, J. Itinerários sobre linguagem via Foucault. Dissertação de Mestrado. Rio de Janeiro: PUC- Rio, 2014. 